\title{
Politics of Language and Linguistic Identity: Sadri Replacing other Adivasi Languages in Sundargarh
}

\author{
Dr. Ajit Kumar Kullu \\ Assistant Professor of English \\ Sambalpur University \\ Jyoti Vihar, Burla, Odisha, India \\ ajitkumarkullu@gmail.com
}

\begin{abstract}
Movements related to languages are interesting phenomena with a load of consequences on the fate of languages. A powerful language with state backing is capable of weakening and dismantling the structure of a language which is less powerful and without any political backings. However, there are languages which find other ways to growth and popularity. People find interesting reasons to switch to a different language. Sadri, tribal lingua-franca in the district of Sundargarh, Odisha is enjoying a privileged linguistic space at the cost of other adivasi languages.
\end{abstract}

Keywords: Sadri, Politics, Language, Identity, Culture, Society

Language is a special and distinguished ability the humans are endowed with. Cognitive Linguistic draws a direct link between language and human body and mind. In a multi lingual context, such as India linguistic identity becomes an important part of the socio, economic and cultural progress of an individual and a community. The generative assimilation of languages and cultures make grounds for new trajectories. The analysts, depending on the schools of thought they belong to, notice the regeneration or degeneration 
in the languages or cultures. Sadri language is now an indispensable lingua franca. In fact it is taken to be a tribal language. Whether it is a tribal language or not is a matter of great debate and discourse. But the new turn of position and privilege Sadri language is accorded and how the other tribal languages get treated become an interesting case of study. More than $70 \%$ of the population in Sundargarh district of Odisha is conversant in Sadri. The spread of this language can be directly linked to the social, political and economic mobilisation of this western district of Odisha.

Most countries and nation states are demarcated on linguistic and cultural contours. A number of times it is languages which draw the boundaries either national or international. The unification of different countries in Europe as well as the reorganisation of the states in India one way or the other look at language as an important point of divide. Whenever a nation gets formed or goes in through the process of getting independence, the nationalist euphoria causes a number of national objects, symbols as well as practices for perpetuating love for the country. Language spoken by the majority or the powerful takes the privilege seats. And thereafter, languages of the minority and the downtrodden face the danger of extinction. A particular language of the state gets a legal and official status. The official communications both in documents or words are transacted in that particular language. Learning of other languages is explicitly discouraged through implicit moves. In these situations the fate of the language depends on the politicians who either choose to promote these languages for appeasement and electoral benefits or destroy them by their nationalistic and patriotic policies. A language with Orature and without a systematic medium of language teaching and learning mechanism suffers more in these situations. A number of Indian languages have been dwindling since the centuries. And it is mostly due to the cultural, political and economic policies of the states. Growth in information technology also contributes to the death of languages. As already mentioned 'language' or 'languages' form 
national or state identity, but what about the dialects of the state language and the other languages which are used by communities and individuals. How does one identify himself with the state when one is unable to communicate in the tongue of the state? This situation alienates the non-speaker of the state language though geographically residing in the geographical and topographical heart of a state. The linguistic identity of such people gets marred and defaced. Their belongingness and allegiance to the state and nation also become problematic. Linguistic identity binds a certain mass of people together who speak a common language. It has a direct bearing on the cultural practices of the people because languages design people to think in a particular way. And similarly the cultural behaviour of a race or community is determined by the language it is cradled in.

Movements related to languages are again interesting phenomena with a load of consequences on the fate of languages. A powerful language with state backing is capable of weakening and dismantling the structure of a language which is less powerful and without any political backings. Languages are colonial in nature. They enter other linguistic territories to consolidate their position. They may establish their places taking over the local languages or go away living the local languages disfigured and mutilated. However, there are instance in which the colonised languages do benefit by presence of a foreign language. Language movements may be a show of strength and campaign to boost a particular language set against the powerful languages. But these movements are always against the languages of on the borderlines and of the tribes and minorities. These movements are against these minor languages because they tend to homogenise through assimilation and appropriation of these minor languages. The linguistic policies of the state play a major role in this scenario. The propagation of Hindi as a state Language of India is being looked at with a lot of suspicion by a number of non-Hindi speaking states. This move of the state is seen as linguistic tyranny because the non Hindi speaking states have absolutely no reason to impose on themselves 
Hindi at the cost of their own languages. There may be arguments that the states take care of the language of the linguistic minorities. The best example of this benevolent move is seen in MLE (Multilingual Education) introduced by governments. However, the move of MLE as deciphered from the notification is to facilitate a smooth transition from the mother tongues of the tribals to the main stream languages. This can be called a bridging movement, again for the benefit of the mainstream language. It therefore once again leads to the same age old idea of homogenisation and hybridisation of linguistic and cultural communities.

Despite its linguistic and cultural diversity, India continues to remain a sovereign state. Multiculturalism and multilingualism is therefore no hindrance to the way of integrity of a nation. There are a number of languages flourishing in the country, some at the expense of others. There are a number of them dying quietly, without experiencing any whimper. There are no state funerals for them, nor academic discourses and dissertations and are thrown to oblivion.

Sadri is one of those languages which has been thriving despite any state backing. The origin of this Eastern Indo-Aryan language, which is also known as Nagpuri can be traced to the Neolithic age in the Chhota Nagpur Plateau. It is spoken mostly in Jharkhand, Odisha, Chhattisgarh, Madhya Pradesh West Bengal and Assam. It used to be a lingua franca a bridge language between the tribes, a language of the bazaars (weekly markets), a bridge of intertribal communications. But gradually this language began to be considered as tribal tongue. Most tribes in Sundargarh speak this language. It has become a natural language of the tribes mostly living in the towns of Sundargarh and Odisha. There has been some appropriation in this case. It is again a matter of debate whether the tribes have appropriated this language or the language has appropriated the tribal linguistic space. But the researchers as well as the tribals themselves have begun to identify themselves with this language. This paves a way for 
the new linguistic identity of the tribal communities who were earlier known by the tribal groups they belonged to.

Information and communication technology has been contributing to the growth and development of Sadri language. Modern technology is mostly to cater to the languages which have a huge number of speakers or are enlisted as scheduled languages. Thanks to the Sadri music industry which came as major booster to Sadri language in the region. Recorded music is replacing the traditional music and dance of the tribals of the district. Sadri music albums which are heavily influenced by mainstream entertainment industry have become increasingly popular in the district. For most of the tribals it has become a matter of status to leave behind their tribal cultural practices and cling onto Sadri as an easy alternative for their own traditions.

Sadri has been flourishing throughout the country. Today $75 \%$ of population in the district can speak or understand Sadri. The petty peddler who used to hawk in Sadri in different villages of Sundargarh can now fluently speak sadri and has a big business establishment in the town frequented by the tribals for their daily need. The business classes in the district have contributed in a large way in making Sadri a popular language. They acquired this language to sell their products and now this is the language they have been using to strengthen their business holds in the district. The advent of sadri songs in audiovisual mode has boosted a popular culture of song and dance in the district. People, including the tribals prefer these songs and dance to their own traditional narratives and poems. The tribal linguistic identity is undergoing a gradual but steady transformation at through Sadri. Sadri has a wider reach and greater promises for the tribals as it provides an alternative modern view of their life style. It is supported by the politics of language as practiced in the district. Sadri is a connecting language for all tribals and non-tribals residing in the district; for politicians it is the language of campaign and political opinions; for 
businessmen it is a language of the market; for religions it is the language of worship and devotion. It has become an effective bridge between the tribal and non-tribal world. When there was a movement to make Jharkhand state, this language was looked at as a unifying force. And most adivasis of the district thought that some parts of the district would become a part of the newly created state of Jharkhand. This was the language of the tribals across the borders of the states of Odisha and Jharkhand, then Bihar. Hindi wasn't the preferred language of communication among the tribals of these two states. It was Sadri which actually created a bond between the people separated by the states' boundary. Of course, most of the tribes in this region have a lot of common grounds. Sundargarh is a part of Chhotanagpur Plateu which came under Chota Nagpur Division (South West Frontier) of British India.

Christianity set foot in the Chotanagpur region in the first part of the $19^{\text {th }}$ century. This was one of the languages used by the missionaries because this lingua franca suited the purpose of the missionaries to address the multitudes from various tribes, speaking different tongues. The twentieth century, especially the 50s and 60s opened up the way for vernaculars to be used in liturgy of the Roman Catholic Church. Sadri along with Hindi became one of the prominent languages used in the church. This strengthened the position of Sadri among the Christian tribal groups which is almost $17 \%$ of the population of the district. In most of the churches, especially in the Roman Catholic parishes, Sadri hymns were composed and prayers were translated into Sadri from Latin and English.

Sadri has today through a process of acculturation propelled by the politics of language has become the linguistic identity of the tribes of Sundargah. Today tribality is synonymous with a language which is not even closer to most of the tribal languages belonging to different families of languages. It now enjoys a privileged place over the tribal languages on the verge extinction. The linguistic division of the population of the district according to the Census 2011, the percentage of population who spoke Odia as their first 
language was $45.96 \%$, Hindi $23.38 \%$, Munda $8.81 \%$, Kurukh (Oraon) $5.57 \%$, Kisan $4.57 \%$ Kharia $4.38 \%$, Mundari $0.80 \%$ Mundari, Santali $0.43 \%$ and others Telegu and Bengali. Amusingly Sadri is not considered to be the first language by the natives of Sundargarh but this language is overshadowing the presence of all other tribal languages in the district. In fact this language has become an alter ego of tribal identity, languages and cultures. It has become a language of tribal unity in the district. 


\section{References}

Hassen R (2016) Language as an Index of Identity, Power, Solidarity and Sentiment in the Multicultural Community of Wollo. J Socialomics 5: 174.

www.longdom.org/open-access/language-as-an-index-of-identity-power-solidarityand-sentiment-in-themulticultural-community-of-wollo-2471-8726-1000174.pdf. 11.04.2019

Kullu, Ajit Kumar. "Linguistic and Cultural Dilemmas of Tribals MLE and Kharia, Munda Oraon and Kisan speaking tribes of Sundargarh District of Odisha”. International Journal of English Language, Literature and Humanities. V IV Is V. www.ijellh.com/OJS/index.php/OJS/article/view/1401/1360. 12.08.2020

Can Translations save the Dying Tribal Dialects? Sadri Taking over Kharia, Munda, Oraon and Kisan Dialects of Western Odisha.” The IJHSS Journal. III, V. May, 2015.www.theijhss.com. June 10, 2015.

Mahmoodi-Shahrebabaki, Masoud. (2018). Language and Identity: A Critique. Journal of Narrative and Language Studies. 6. 22.08.2020 www.researchgate.net/publication/331197439

Mohan, Shailendra. (2013). Linguistic identity and language preferences among the austroasiatic language speakers of jharkhand. www.researchgate.net/publication/303013753. 22.08.2020

Moseley, Christopher ed. Encyclopedia of World's Endangered Languages. www.droppdf.com/files/6Ulq1/encyclopedia-of-world-s-endangered-languages.pdf. 18.12 .2014

Rovira, Lourdes C., y “The Relationship between Language and Identity. The Use of the Home Language as a Human Right of the Immigrant." Remhu - Revista 
Interdisciplinary Da Mobilidade Humana, Vol. 16, No. 31, 2008, Pp.63-81. Redalyc, www.Redalyc.Org/Articulo.Oa?Id=407042009004. 24.08.2020

Sundargarh District.Odisha Review.

www.magazines.odisha.gov.in/Orissareview/2010/December/engpdf/189-195.pdf. 10.08.2020. 